\title{
Primary aorto-esophageal fistula: Great masquerader of esophageal variceal bleeding
}

\author{
Laxmi Kokatnur, Mohan Rudrappa
}

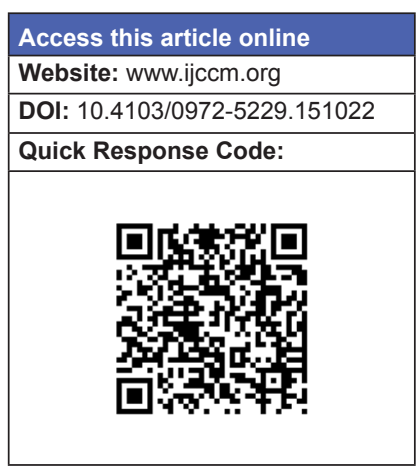

\section{Introduction}

Upper gastrointestinal bleeding (UGIB) is a major cause of mortality and morbidity accounting for about $56.5 / 100,000$ hospitalization with a mortality rate of $8.2 \% \cdot{ }^{[1,2]}$ Aorto-esophageal fistula (AEF), an abnormal anatomical communication between the aorta and esophagus is a rare cause of UGIB. Thoracic aneurysm is the most common cause of this condition. ${ }^{[3]}$ As the thoracic aneurysm grows in size, the increasing tension on its wall will erode the aorta and rupture into the surrounding esophagus leading to uncontrolled bleeding. ${ }^{[4]}$ As ulcer related or variceal bleeding constitutes for most of the UGIB bleeding, even in elderly who are at risk of AEF and the inability of the esophagogastroduodenoscopy (EGD) to detect most cases, AEF is often not diagnosed timely. ${ }^{[5]}$ The sensitivity of EGD for detection of AEF is around $25 \%$. All these factors make the timely diagnosis of AEF challenging, and at times missed altogether leading to

From:

Family Medicine and Pulmonary and Critical Care Medicine, University of Arkansas for Medical Science, Little Rock, USA

\section{Correspondence:}

Dr. Laxmi Kokatnur, 601 Napa Valley Drive, Apartment 234, Little Rock, AR 72211, USA.

E-mail: drlaxmisk@gmail.com catastrophic consequences. We present a case of AEF which was initially treated as variceal bleeding and later promptly diagnosed with computed tomography (CT).

\section{Case Report}

A 70-year-old male patient with hypertension with regular ethanol use, presented to a local hospital with complaints of hematemesis and melena from the past 1-day. He was hemodynamically stable on presentation with initial hemoglobin level of $7.2 \mathrm{~g} / \mathrm{dl}$. He underwent timely EGD, which showed grade 1 mid and distal esophageal varices without any active bleeding. Subsequently, his condition deteriorated with the development of hypotension and transferred to our medical center for further management. Repeat EGD showed a small Mallory-Weiss tear without active bleeding along with the presence of large blood clots in the gastric fundus. Esophageal varices were not seen in this EGD. As the source of bleeding was not clear despite two EGD and clinical evidence of GI bleeding, he underwent emergent colonoscopy which once again failed to detect any source lower GI bleeding. His condition got stabilized with blood transfusions and supportive management. However, later in the day, he developed massive hematemesis and hematochezia 
leading to persistent hemorrhagic shock. Emergent intubation was done for airway protection, massive transfusion protocol was initiated, and a CT angiogram was performed. It revealed type $\mathrm{B}$ aortic dissection with rupture and the active extravasation of blood into the esophagus, confirming the diagnosis of AEF [Figure 1]. He underwent emergency percutaneous thoracic endovascular aortic repair with aortic stent placement [Figure 2]. His shock resolved hemoglobin stabilized and did not have any more episodes of bleeding thereafter. Repeat EGD showed a 3-cm opening in the midesophagus with ragged and irregular borders, not seen earlier EGDs. His hospital course was complicated by the infection of the endograft which was replaced and fortified with an omental flap and being is presently being, followed by for reconstruction surgeries.

\section{Discussion}

Aorto-esophageal fistula is an abnormal anatomical communication between the aorta and esophagus. In 1818 , Dubrueil described this condition for the $1^{\text {st }}$ time in a French soldier who ingested a beef rib, leading to massive hematemesis. ${ }^{[6]}$ Almost a century later, Chiari described the triad of midthoracic pain, herald hemorrhage, and fatal hematemesis seen in these patients..$^{[7]}$ The exact incidence of this condition is not known, as the vast majority of these patients die before a definitive diagnosis can be made. In the past, infections such as tuberculosis and syphilis, leading to aortitis were the common cause of this condition. In this antibiotics era, thoracic aortic aneurysm constitutes for more than half of these cases.$^{[8]}$ Other causes
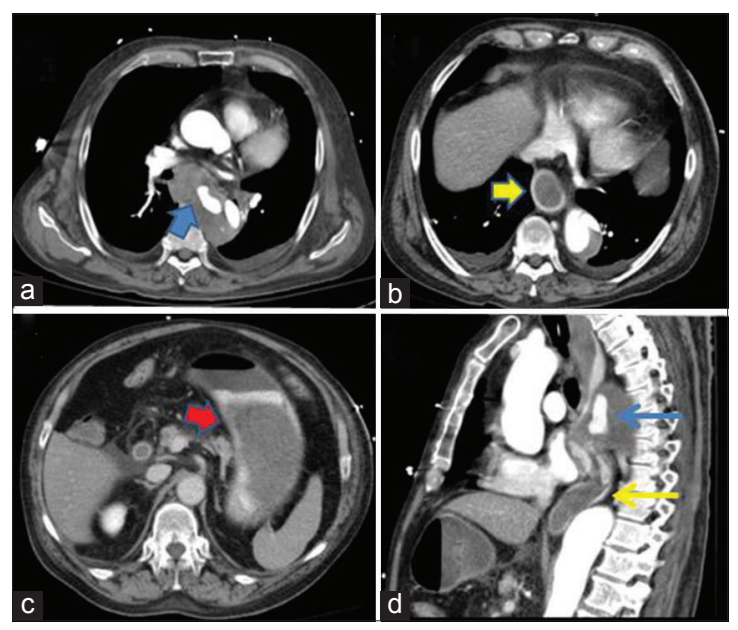

Figure I: Selected images from computed tomography angiogram. (a) Communication and extravasation between aortia and esophagus (blue arrow head) in the arterial phase. (b) Accumulation of blood in lower esophagus in venous phase (yellow arrow head). (c) Significant accumulation of blood in the stomach in the kidney delay images (red arrow head). (d) Sagittal reconstruction images shows commination (blue arrow) and extravasation (yellow arrow) of blood between aorta and esophagus described in the literature are cancer, acid reflux disease, trauma, caustic ingestion, and esophageal biopsies. ${ }^{[3,8]}$ AEFs are classified as primary if they are caused by the spontaneous erosion of the aortic wall into the esophagus and as secondary if they occur as a complication following aortic or esophageal surgeries. Owing to the increasing number of interventions of the aorta, secondary AEF is 10 times more common than primary. ${ }^{[8]}$

The herald bleeding described by Chiari is only seen in half of these patients. ${ }^{[8]}$ Once the bleeding starts, rapid extravasation from aorta will cause a sudden drop in blood pressure. This will facilitate a clot formation leading to the temporary cessation of bleeding. This constitutes initial herald bleeding described by Chiari. With continued resuscitation, the blood pressure will raise again dislodging the fresh and loose clot around the AEF leading to terminal bleeding. Commonly used resuscitation fluids including pseudo random binary sequence lack adequate clotting factors add to the compromise of clot integrity. Unlike in other structures, the lax mediastinum around the aorta and esophagus prevent autotamponade, to prevent persistent extravasation of blood. These factors can contribute to torrential bleeding, the final hematemesis as described by Chiari. ${ }^{[8]}$ The time between herald hemorrhage and final bleeding varies from hours to days. ${ }^{[9]}$

The risk of aortic aneurysm increases with age, with an incidence of $12.5 \%$ in elderly Americans. ${ }^{[10]}$ Half of all cases of UGIB are also described in this age group. The sensitivity of EGD to identify the source of bleeding in other causes of UGIB is $90 \%$, but for AEF it is $<10 \%$. . $^{[5,11]}$ It may show pulsatile mass, bluish discoloration, or simply blood clotting in the esophagus in one-third of cases. ${ }^{[4]}$ In our case, two EGDs showed no evidence of AEF. A CT arteriogram is diagnostic in most cases,

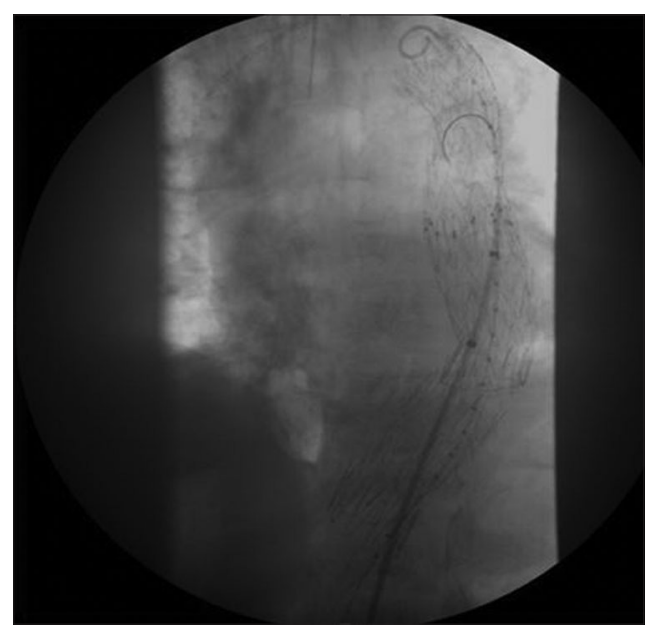

Figure 2: Endovascular graft in the thoracic aorta 
which show active extravasation of blood from the aorta to esophagus.

Once diagnosed, AEF should be treated with emergent aortic stenting to control the bleeding. Owing to contamination from the GI tract, one-quarter of stents become infected. ${ }^{[12]}$ Apart from broad-spectrum antibiotics and antifungals, thorough mediastinal debridement may be required for adequate infection control. Once the infection is controlled, the complex aortic and esophageal reconstruction is done in multiples stages. AEF, once considered to be uniformly fatal, is now a treatable condition with timely intervention.

\section{Conclusion}

Aorto-esophageal fistula is a rare, but life-threatening condition presenting as UGIB. A high level of suspicion is needed, as routine tests performed for UGIB typically only detect one-third of cases. Avoiding over-resuscitation can be helpful in preventing subsequent hemorrhages. A stepwise surgical approach is also beneficial in most cases.

\section{References}

1. Straube S, Tramèr MR, Moore RA, Derry S, McQuay HJ. Mortality with upper gastrointestinal bleeding and perforation: Effects of time and NSAID use. BMC Gastroenterol 2009;9:41.
2. Feinstein LB, Holman RC, Yorita Christensen KL, Steiner CA, Swerdlow DL. Trends in hospitalizations for peptic ulcer disease, United States, 1998-2005. Emerg Infect Dis 2010;16:1410-8.

3. Göbölös L, Miskolezi S, Pousios D, Tsang GM, Livesey SA, Barlow CW, et al. Management options for aorto-oesophageal fistula: case histories and review of the literature. Perfusion 2013;28:286-90.

4. Amin S, Luketich J, Wald A. Aortoesophageal fistula: case report and review of the literature. Dig Dis Sci 1998;43:1665-71.

5. Chak A, Cooper GS, Lloyd LE, Kolz CS, Barnhart BA, Wong RC. Effectiveness of endoscopy in patients admitted to the intensive care unit with upper GI hemorrhage. Gastrointest Endosc 2001;53:6-13.

6. Drbrueil. Observation Sur La Perforation De L'esophage Et De L'arta Thoracique Par Une Partion D'os Avale. Aves Des Reflexions. J Univ Sci Med 1818;9:357-65.

7. Chiari H. Uber Pemdkorperverletzung Des Oesopgagus Mit Aortenperforation. Berl Kiln Wochenschr 1914;51:7.

8. Hollander JE, Quick G. Aortoesophageal fistula: A comprehensive review of the literature. Am J Med 1991;91:279-87.

9. Sweeney MS, Gadacz TR. Primary aortoduodenal fistula: Manifestation, diagnosis, and treatment. Surgery 1984;96:492-7.

10. Go AS, Mozaffarian D, Roger VL, Benjamin EJ, Berry JD, Borden WB, et al. Executive summary: heart disease and stroke statistics - 2013 update: A report from the American Heart Association. Circulation 2013;127:143-52.

11. Yachimski PS, Friedman LS. Gastrointestinal bleeding in the elderly. Nat Clin Pract Gastroenterol Hepatol 2008;5:80-93.

12. Watanabe Y, Kashihara S, Kiyonari N, Tsuji Y, Hisano K, Okada M. Combined resection of the thoracic esophagus and thoracic descending aorta. Jpn J Thorac Cardiovasc Surg 1999;47:495-8.

How to cite this article: Kokatnur L, Rudrappa M. Primary aorto-esophageal fistula: Great masquerader of esophageal variceal bleeding. Indian J Crit Care Med 2015;19:119-21.

Source of Support: Nil, Conflict of Interest: None declared 